\title{
Production of sound waves by bacterial cells and the response of bacterial cells to sound
}

\author{
Michio Matsuhashi, ${ }^{*}$ Alla N. Pankrushina, ${ }^{3}$ Satoshi Takeuchi, ${ }^{3}$ Hideyuki Ohshima, Housaku Miyoi, \\ Katsura Endoh, Ken Murayama, Hiroshi Watanabe, Shigeo Endo, Mikio Tobi, Yoshihiro Mano, \\ Masao Hyodo, Torakichi Kobayashi, ${ }^{1}$ Tomohiko Kaneko, ${ }^{3}$ Sugio Otani, ${ }^{2}$ \\ Susumu Yoshimura, ${ }^{3}$ Akira Harata, ${ }^{4, * \star}$ and Tsuguo Sawada ${ }^{4}$ \\ Department of Biological Science and Technology, ${ }^{1}$ Department of Information and Communication Technology, and \\ ${ }^{2}$ Department of Material Science and Technology, Tokai University, Numazu 410-0321, Japan \\ ${ }^{3}$ Yoshimura $\pi$-Electron Project, ERATO, Japan Science and Technology Corporation, c/o Matsushita Research Institute Tokyo, \\ Inc., Higashimita, Tama-ku, Kawasaki 214-0033, Japan \\ ${ }^{4}$ Department of Industrial Chemistry, The University of Tokyo, Bunkyo-ku, Tokyo 113-0033, Japan
}

(Received October 27, 1997; Accepted February 18, 1998)

\begin{abstract}
Bacterial cells enhance the proliferation of neighboring cells under stress conditions by emitting a physical signal. Continuous single sine sound waves produced by a speaker at frequencies of 6-10, 18-22, and $28-38 \mathrm{kHz}$ promoted colony formation by Bacillus carboniphilus under non-permissive stress conditions of high $\mathrm{KCl}$ concentration and high temperature. Furthermore, sound waves emitted from cells of Bacillus subtilis at frequencies between 8 and $43 \mathrm{kHz}$ with broad peaks at approximately $8.5,19,29$, and $37 \mathrm{kHz}$ were detected using a sensitive microphone system. The similarity between the frequency of the sound produced by $B$. subtilis and the frequencies that induced a response in $B$. carboniphilus and the previously observed growth-promoting effect of $B$. subtilis cells upon $B$. carboniphilus through iron barriers, suggest that the detected sound waves function as a growth-regulatory signal between cells.
\end{abstract}

Key Words_Bacillus carboniphilus; Bacillus subtilis; bacteria; growth regulation; signal response; sonic signal; sound; ultrasonic

Cell biologists often have difficulty culturing highly diluted animal or plant cells (Watson et al., 1993). Once the cells reach a certain density, their growth is markedly facilitated. Individual cells probably produce a signal or signals that stimulate the growth of other cells. However, the signal intensity is too weak in diluted cultures unless a layer of homologous or foreign cells, called a feeder layer or host or nurse cells, is added to the diluted culture (Muir et al., 1954). Even unicellular microorganisms cannot form colonies on an agar plate if inoculated under unfavorable growth conditions such as high salt concentrations or high temperatures (Matsuhashi et al., 1995). However, they do start to grow and form colonies under these condi-

* Address reprint requests to: Dr. Michio Matsuhashi, Department of Biological Science and Technology, Tokai University, 317 Nishino, Numazu, Shizuoka 410-0321, Japan.

** Present address: Department of Molecular Science and Technology, Graduate School of Engineering Sciences, Kyushu University, 6-1 Kasuga-koen, Kasuga 816-8580, Japan. tions, which are ordinarily non-permissive, when they receive signals from large growths of neighboring homologous or heterologous cells (Matsuhashi et al., 1997b). Certain chemicals may play an important role in this cell-to-cell growth regulation (Kaiser and Losick, 1993; Swift et al., 1996). Recently, we proposed another type of intercellular regulation involving physical rather than chemical signals. These signals could be sonic. The effect of growth-promoting and sustaining signals can be seen in a mass of cells growing on the same surface of a nutrient-containing agar plate, even when in Petri dishes separated by a 1-2 mm-thick iron barrier (Matsuhashi et al., 1996). This newly discovered type of intercellular signaling appears to function in a variety of cells (Matsuhashi et al., 1996, 1997b).

In this paper, we report the response of a newly isolated bacteria, Bacillus carboniphilus strain Kasumi 6 (Fujita et al., 1996; Matsuhashi et al., 1995), to sound emitted from a speaker. $B$. carboniphilus requires carbon in the form of graphite or charcoal to grow under 
conditions that are ordinarily non-permissive. We chose this strain of bacteria for measuring bacterial growth-response to sound because this strain is the most sensitive signal recipient in tests of the remote growth-promoting effects of $B$. subtilis cells (Matsuhashi et al., 1996). Graphite is believed to convert external electromagnetic energy into sound (Matsuhashi et al., 1997a). We also report the detection of sonic signals produced by $B$. subtilis cells using a very sensitive, pressure-type condenser microphone system. B. subtilis was used for this study because this species is the most effective intercellular growth facilitator of the bacteria tested (Matsuhashi et al., 1996, 1997b).

\section{Materials and Methods}

Strains of bacteria and culturing conditions. B. carboniphilus strain Kasumi 6 (Fujita et al., 1996; Matsuhashi et al., 1995) was from our stock culture. The bacteria was cultured on an agar plate containing $15 \mathrm{~g}$ agar (Wako Chemical Co., Osaka, Japan, purest reagent grade) and Bacto Antibiotic Medium 3 (Difco Laboratories, Detroit, MI, USA) $8.75 \mathrm{~g}$ per liter at $37^{\circ} \mathrm{C}$ for several days, until spores developed. For the sonic signal recipient study, the spores were suspended in deionized water at a concentration of about $10^{6}$ spores per milliliter. To measure the response of the bacteria to sound, $1-3 \times 10^{3}$ viable bacteria were inoculated onto an agar plate in a $90 \times 15 \mathrm{~mm}$ polystyrene Petri dish. The medium used produced non-permissive stress conditions and consisted of $15 \mathrm{~g}$ of agar, $8.75 \mathrm{~g}$ of Bacto Antibiotic Medium 3 and $10 \mathrm{~g}$ of $\mathrm{KCl}$ per liter. The number of viable spores in the aqueous suspension was measured by inoculating an aliquot of the suspension onto an agar plate containing $15 \mathrm{~g}$ of agar and Trypticase Soy Broth (BBL, Becton Dickinson, Cockeysville, MD, USA) $30 \mathrm{~g}$ per liter, and incubating the plate at $37^{\circ} \mathrm{C}$ for 4 days.

Cells of $B$. subtilis Marburg strain JH642 (phe-1 trpC2) (Perego and Hoch, 1991), which were used to measure sound production, were cultured at $37^{\circ} \mathrm{C}$ for 1 day and then at $20^{\circ} \mathrm{C}$ for an additional day on an Lagar plate (Lennox, 1955). The medium was slightly modified. It consisted of $10 \mathrm{~g}$ of polypeptone, $5 \mathrm{~g}$ of yeast extract, $1 \mathrm{~g}$ of glucose, $5 \mathrm{~g}$ of sodium chloride and $20 \mathrm{mg}$ of thymine per liter, and was adjusted to $\mathrm{pH} 7.0$ with $\mathrm{NaOH}$ to obtain maximum growth of the bacteria.

Measurement of the sonic response by $B$. carboniphilus. An artificial sound was produced by a function generator (Iwatsu FG330, 600-ohm output impedance) connected to a speaker (Ohm SP-88 fullrange speaker, $65 \times 100 \times 65 \mathrm{~mm}[w \times h \times t]$, 8-ohm impedance, $1.5 \mathrm{~W}$ output and $90 \mathrm{~dB}$ intensity). The sound was a continuous sine wave produced at distinct frequencies between 1 and $50 \mathrm{kHz}$. The function generator was used at a fixed internal voltage setting of $10 \mathrm{~V}$. The actual wattage was measured as $22 \mathrm{~mW}$ at $10 \mathrm{kHz}, \quad 38 \mathrm{~mW}$ at $20 \mathrm{kHz}, 50 \mathrm{~mW}$ at $30 \mathrm{kHz}$ and $55 \mathrm{~mW}$ at $40 \mathrm{kHz}$. The intensity of the sound, at the surface of the agar plate $0.5 \mathrm{~cm}$ from the speaker, measured through a $1 \mathrm{~mm}$-thick polystyrene Petri dish cover was approximately $360 \mathrm{mV}$ or $0.070 \mathrm{~Pa}$ at $1 \mathrm{kHz}, 6.9 \mathrm{mV}$ or $0.007 \mathrm{~Pa}$ at $20 \mathrm{kHz}$ and undetectable at $49.8 \mathrm{kHz}$ after correction for the sensitivity of the microphone. The intensity of the sound measured at $5 \mathrm{~cm}$ above the speaker (omitting the dish cover) was approximately $390 \mathrm{mV}$ or $0.07 \mathrm{~Pa}$ at $1 \mathrm{kHz}, 240 \mathrm{mV}$ or $0.096 \mathrm{~Pa}$ at $10 \mathrm{kHz}, 152 \mathrm{mV}$ or $0.16 \mathrm{~Pa}$ at $20 \mathrm{kHz}$, $7.9 \mathrm{mV}$ or $0.015 \mathrm{~Pa}$ at $30 \mathrm{kHz}, 1.0 \mathrm{mV}$ or $2.78 \times 10^{-3}$ $\mathrm{Pa}$ at $40 \mathrm{kHz}$ and $0.35 \mathrm{mV}$ or $1.36 \times 10^{-3} \mathrm{~Pa}$ at $50 \mathrm{kHz}$.

Apparatus for detecting the sonic waves produced by $B$. subtilis. The sound waves generated by $B$. subtilis cells were detected using a sensitive pressure condenser microphone (Type 4144, Brüel \& Kjaer, Denmark) connected to a preamplifier (Type 2819, Brüel \& Kjaer) with a pressure sensitivity of $52.5 \mathrm{mV} / \mathrm{Pa}$ below $8.2 \mathrm{kHz}(-3 \mathrm{~dB})$. The acoustic signal intensity was measured using an apparatus for photoacoustic measurement (Yoshinaga et al., 1989) but this time with using no external light source. The internal volume of the photoacoustic cell was $0.5 \mathrm{~cm}^{3}$. The microphone output was fed into a $40 \mathrm{~dB}$ amplifier (Type LI-75A, NF Corporation, Yokohama, Japan) and the signal of every two microsecond interval was converted during $64 \mathrm{k}$-long words by a 12-bit A/D converter. The recorded signals were pooled in 4096word datasets. Each set was analyzed by a Fourier transformation using a Hanning window, and the power spectra were averaged over the $64 \mathrm{k}$-word samples. Sensitivity of the detection system depended on the acoustic frequency, because there was acoustic resonance within the apparatus (sample-microphone room), and because the sensitivity of the microphone decreased at frequencies higher than $8.2 \mathrm{kHz}$. The resonance frequencies observed were $0.68,6.0,7.7,17,28$, and $50 \mathrm{kHz}$. The overall sensitivity of the microphone to the sonic signal generated inside the photoacoustic cell was calibrated experimentally using a photoacoustic signal source. The sensitivity was $0 \mathrm{~dB}$ below $1 \mathrm{kHz},-30 \mathrm{~dB}$ from 5 to $15 \mathrm{kHz},-10 \mathrm{~dB}$ from 15 to $18 \mathrm{kHz},-25 \mathrm{~dB}$ from 20 to $32 \mathrm{kHz},-50 \mathrm{~dB}$ from 35 to $45 \mathrm{kHz}$ and $-30 \mathrm{~dB}$ from 47 to $50 \mathrm{kHz}$, with $0 \mathrm{~dB}$ referring to $52.5 \mathrm{mV} / \mathrm{Pa}$.

\section{Results}

Response of B. carboniphilus to sound

A Petri dish containing a non-permissive stress agar 

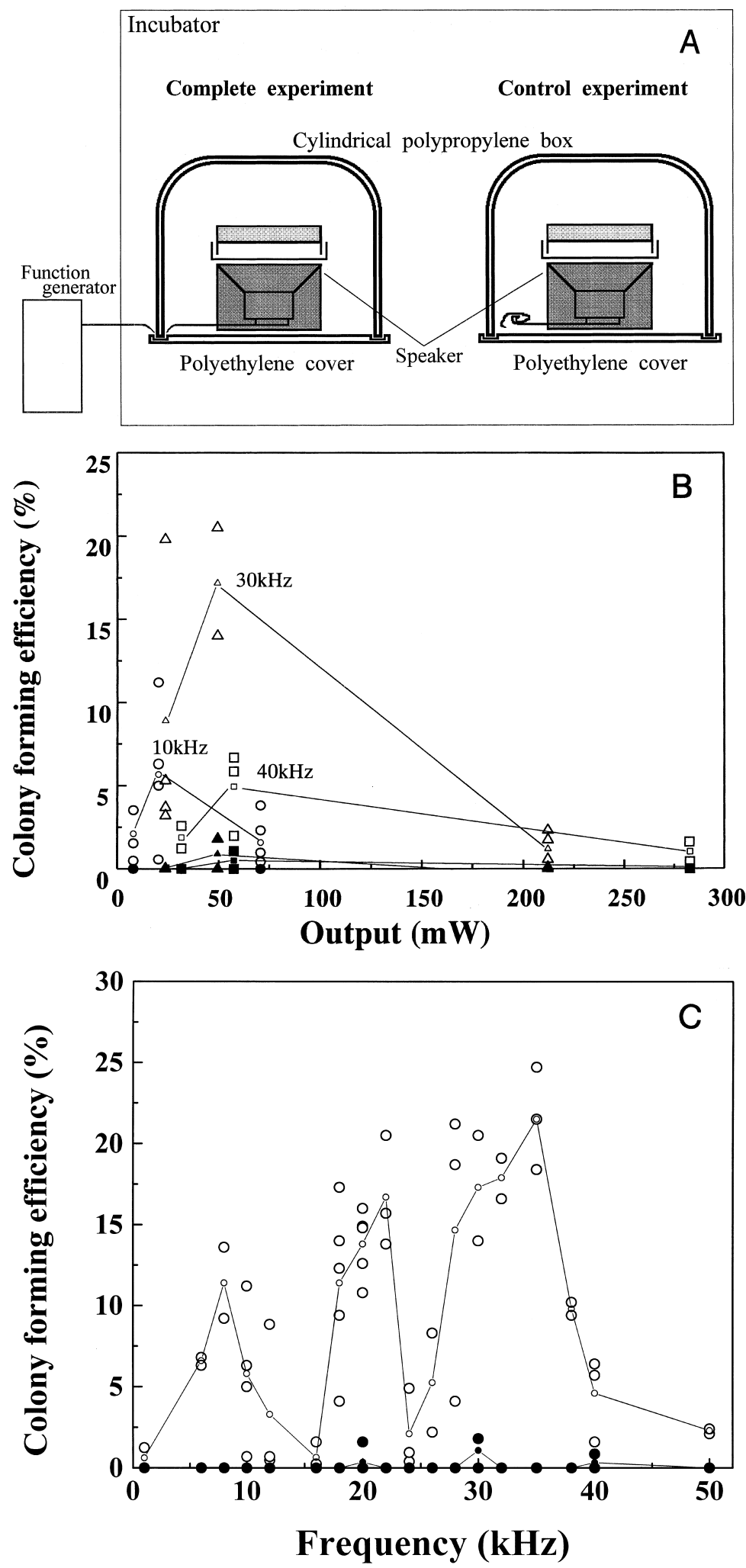

Fig. 1. Promotion of the growth of Bacillus carboniphilus by artificially produced sound.

(A) The experimental apparatus. (B) The effect of wattage on the efficiency of colony formation induced by sounds at $10(O)$, $30(\triangle)$, and $40 \mathrm{kHz}(\square)$. For experimental details, see the legend to $C$. (C) The efficiency of $B$. carboniphilus colony formation (\%) growing under $\mathrm{KCl}$ stress $(8.75 \mathrm{~g}$ of Bacto Antibiotic Medium $3,10 \mathrm{~g}$ of $\mathrm{KCl}$ and $15 \mathrm{~g}$ of agar per liter) plotted at various frequencies at $2 \mathrm{kHz}$ intervals. The sounds were emitted from a speaker connected to a function generator set at $10 \mathrm{~V}$. The open symbols represent the values obtained in experiments repeated 2-5 times, and the closed symbols correspond to control experiments run simultaneously. The small symbols indicate the mean values. See the text for experimental details. 
plate inoculated with $B$. carboniphilus was inverted and placed on a speaker (Fig. 1A). The dish and speaker were placed in a cylindrical polypropylene container, which had dimensions of $142 \times 92 \times 2 \mathrm{~mm}$ $[w \times h \times t]$ and was inverted with the polyethylene cover on the bottom. This was incubated at $43.5-44^{\circ} \mathrm{C}$ for 2 days. The number of colonies was counted and the ef-

Table 1. Disappearance of the growth-promoting effect of an artificially generated $35 \mathrm{kHz}$ sound after destroying the paper cone of the speaker.

Normal cone Ruined cone No power

\begin{tabular}{lrll}
\hline Average of 5 experiments & 16.6 & 3.3 & 0.5 \\
Standard error & 7.4 & 3.3 & 0.7
\end{tabular}

Numbers are the efficiency of colony formation expressed as a percentage. The details of the experiment are described in MATERIALS AND METHODS. Power $53 \mathrm{~mW}$. ficiency of colony formation was determined. Control experiments were run with the speaker not connected to the function generator (Fig. 1A) or with a similar speaker connected to the function generator, in which the paper speaker cone was destroyed (Table 1).

Figure 1B shows the effect of wattage on the efficiency of colony formation induced by sounds at 10 , 30 , and $40 \mathrm{kHz}$. With the output voltage of the function generator fixed at 5,10 and $20 \mathrm{~V}$, the most efficient colony formation occurred at $10 \mathrm{~V}$ in three experiments (i.e., $22 \mathrm{~mW}$ at $10 \mathrm{kHz}, 50 \mathrm{~mW}$ at $30 \mathrm{kHz}$ and $55 \mathrm{~mW}$ at $40 \mathrm{kHz}$ ). Therefore, all subsequent experiments at different frequencies were performed using this fixed voltage (Fig. 1C). Figure $1 C$ shows that $B$. carboniphilus responded to continuous single sine wave sounds around $6-10,18-22$, and $28-38 \mathrm{kHz}$ by forming colonies under the non-permissive conditions of $\mathrm{KCl}$ stress and high temperatures. The measure-
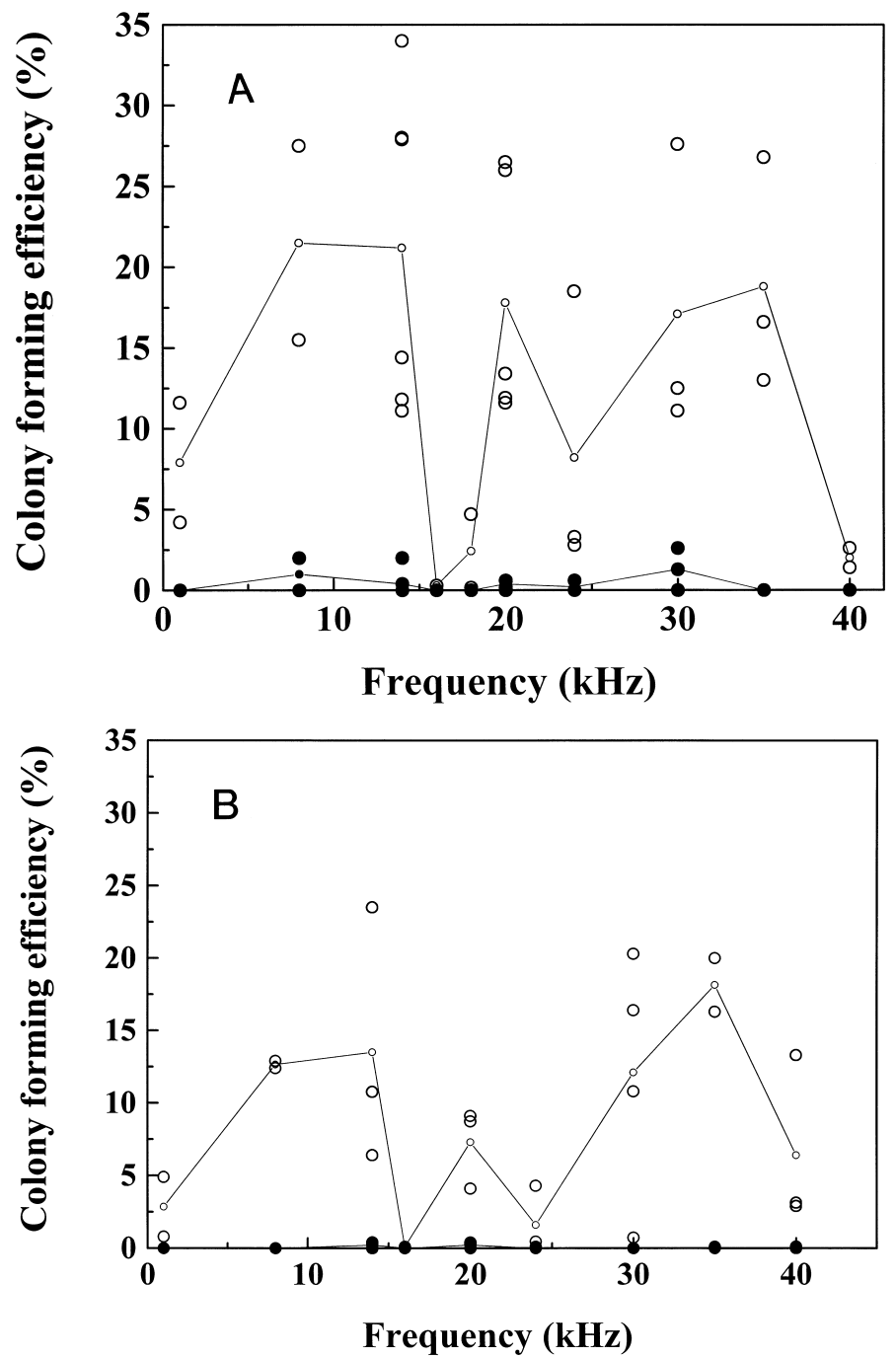

Fig. 2. Effect of altering the size of the polypropylene container (A) or Petri dish (B).

The experimental setup and spectra are similar to those shown in Fig. 1. (A) A larger polypropylene container $(190 \times 145 \times 2 \mathrm{~mm}[h \times w \times t])$ or $(B)$ a smaller Petri dish $(60 \times 15 \mathrm{~mm})$ was used. For symbols see the legend to Fig. $1 \mathrm{C}$. 
ments were repeated 2 to 5 times (large symbols), and the mean values are shown with small symbols.

Similar results were obtained when the Petri dish was placed on pieces of polystyrene foam so that it was $1 \mathrm{~cm}$ above the speaker. The colony-forming efficiency in triplicate experiments was (in percent) 1.3, 5.2 , and 7.5 in the Petri dish placed directly on the speaker, and 3.5, 5.4, and 7.6 in the Petri dish placed above the speaker; when different sized Petri dishes were used $(60 \times 15 \mathrm{~mm}$ and $90 \times 15 \mathrm{~mm})$, when the Petri dish and speaker were enclosed in a larger cylindrical polypropylene container $(190 \times 145 \times 2 \mathrm{~mm}[w \times$ $h \times t])$, when a different sized speaker was used (Tokyo Mark TS-150, 60×85 $\times 25 \mathrm{~mm}[w \times h \times t]$, 8-ohm impedance), or when vegetative cells were used instead of spores. Some of these results are shown below.

Figure 2 shows that varying the size of the plastic container (A) and Petri dish (B) did not have a discernible effect on the frequencies that promoted colony formation by $B$. carboniphilus. Colony formation also occurred at frequencies of $8,15,20$, and $35 \mathrm{kHz}$ when a smaller speaker (Tokyo Mark TS-150) was used.

\section{Sound production by $B$. subtilis}

Approximately $10^{10}$ freshly grown cells of $B$. subtilis Marburg strain $\mathrm{JH} 642$, with a wet weight of $50 \mathrm{mg}$, were mounted on a $1.5 \%$ agar disk $7 \mathrm{~mm}$ in diameter and $1 \mathrm{~mm}$ thick and placed at the bottom of a sample holder (inside diameter, $8 \times 2 \mathrm{~mm}[w \times h]$ ).

Figure 3 shows the spectra of sonic emission as a function of the frequency in a typical experiment. The sonic emission was scanned at frequencies between 1 and $50 \mathrm{kHz}$. The background sound levels were measured in a similar manner when there were no cells in the apparatus. In the presence of cells, three broad peaks were observed at 8 to $10 \mathrm{kHz}, 18$ to $22 \mathrm{kHz}$ and 27 to $43 \mathrm{kHz}$. A sharp peak was seen at $49.5 \mathrm{kHz}$ both in the presence and absence of cells. This sharp peak may have been caused by electronic noises throughout the apparatus used. Three other sharp peaks at 16,25 , and $48 \mathrm{kHz}$ were detected only when cells were present, and not in background measurements taken before and after measurements with the cells.

The measurements were repeated under different climatic and physiological conditions, and with different preparations of $B$. subtilis cells at different stages of growth. The results shown in Fig. 3 were reproduced two more times when measured at an interval. Two other samples gave multiple broad peaks at 9 , 14, 18, 29 (major peak), 32, and $34 \mathrm{kHz}$ in 70 measurements. Other samples gave no significant signals. There were no positive results with heat-killed $B$. subtilis cells. No significant sound production by $B$. carboniphilus, Escherichia coli or Saccharomyces cerevisiae cells has yet been detected.

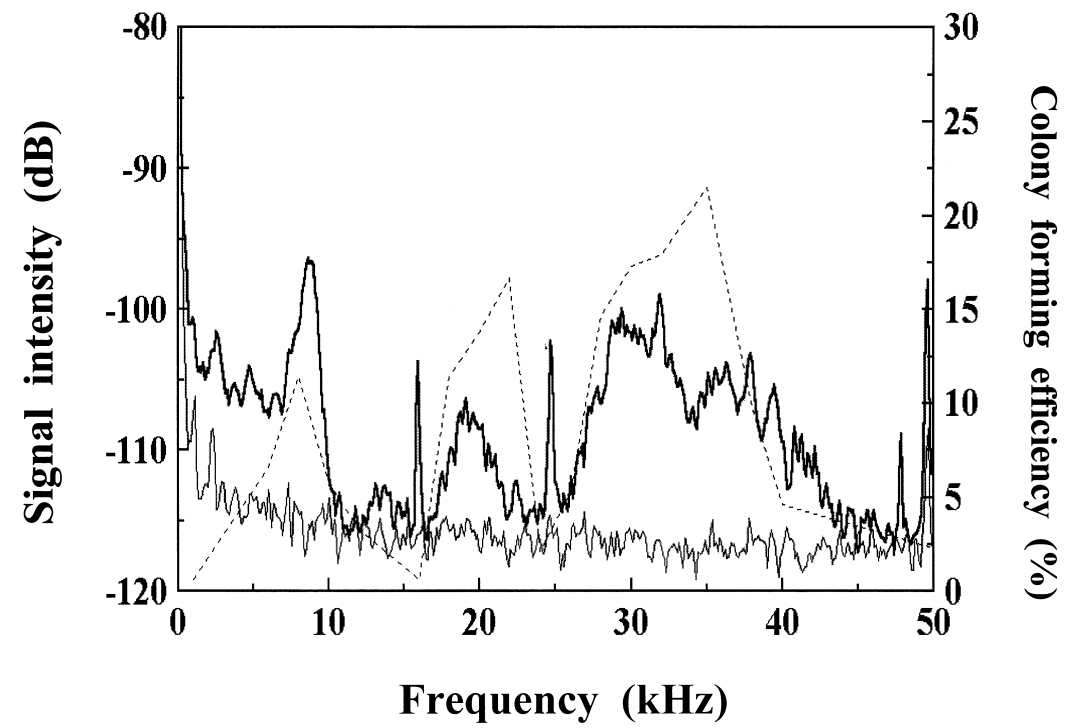

Fig. 3. Sounds emitted by $B$. subtilis cells.

About $50 \mathrm{mg}$ of a cell paste from freshly grown cultures on an agar plate was placed on a small L-agar disk $(8 \times 1 \mathrm{~mm}[d \times t])$ mounted in a quartz sample holder. In control experiments, the cell paste was omitted. The room temperature was about $20^{\circ} \mathrm{C}$. The thick line is the intensity $(\mathrm{dB})$ of sound detected by the microphone. The thin line is the result of the control experiments. The ordinate is the acoustic intensity at $52.5 \mathrm{mV} / \mathrm{Pa}$ at $0 \mathrm{~dB}$, and the abscissa is the frequency in kilohertz. The data are the average of 31 overlapping measurements with 2,048 points each. For comparison, the data of the experiment of Fig. $1 \mathrm{C}$ is also shown with a thin dotted line. 


\section{Discussion}

The sound emitted from billions of cells is probably a cacophony. It is a mixture of a vast number of sounds at slightly different frequencies producing a spectrum with broad peaks. Such a complex sound may be so-called white noise, with a non-repetitive waveform. It is difficult to isolate the sound produced by individual cells to measure the intensity. The spectra of the sonic waves shown in Fig. 3 consist of complex waves with rather broad peaks around a fundamental wave at a frequency of $8.5-9 \mathrm{kHz}$ and its harmonics. Three sharp peaks at 16, 25, and $48 \mathrm{kHz}$ were detected among the broad peaks. These sharp peaks are thought to be the result of the resonance of sounds produced by the bacteria within the photoacoustic cell.

The frequencies of sound that stimulated the growth of $B$. carboniphilus under $\mathrm{KCl}$-stress resembled the pattern of broad peaks of sounds produced by $B$. subtilis cells. Although there were enormous differences in the intensities of the sounds produced by $B$. subtilis and the speaker used to stimulate $B$. carboniphilus, the similarity of their spectra (broad peaks) is noteworthy. Previous results suggested that the signals emitted by $B$. subtilis promote the growth of $B$. carboniphilus (Matsuhashi et al., 1996). This further supports the relationship between the sound emitted by one strain of bacteria and response to the sound by a related strain. We propose that these growth-regulating signals be called "biosonics."

$B$. subtilis emitted the strongest sound detected so far, however, it did not respond to artificially generated sounds under the present experimental conditions. $B$. subtilis is resistant to high temperature $\left(52^{\circ} \mathrm{C}\right)$ and salt concentrations $(15 \% \mathrm{KCl})$. So far, we have been unable to optimize the experimental conditions for measuring the sonic response of this bacterium.

The mechanisms involved in the production and perception of sound waves at specific frequencies are unknown. Cells emit and perceive sounds at wavelengths that exceed the size of the cell. Sounds might be produced by repeated expansion and contraction. This might be accomplished by using intracellular structures, such as membranes, cytoskeleton-like structures (e.g., Casarégola et al., 1990; Okada et al., 1994) or chromosomes, through mechanisms that involve the conversion of ATP or membrane potentials to movement. Activation of an ion channel might be the mechanism for the perception of sound. Such ion channels might have evolved into the acoustic sensing apparatus of higher animals.

In this paper, we report that the growth of $B$. carboniphilus is markedly enhanced by sounds at appropriate frequencies between 6 and $40 \mathrm{kHz}$. The growth of $\mathrm{KCl}$-stressed $\mathrm{E}$. coli, however, was found to be inhibited by sounds at lower frequencies (Matsuhashi et al., unpubl.).

The presence of sonic signaling might not be limited to bacteria. Unpublished studies suggest the existence of a similar mechanism in the yeast $S$. cerevisiae, bean seedlings (Vigna mungo) and developing fish eggs (Matsuhashi et al., unpubl.). Microwaves (Grundler et al., 1977) have also been suspected of affecting the growth of yeast cells and the magnetic fields of yeast and bacterial cells (Kimball, 1937; Moore, 1979).

Previously, we observed that carbon, in the form of graphite and activated charcoal, exerted a remote growth-promoting effect on bacterial cells. It is postulated that this effect results from the conversion of electromagnetic radiation into sonic waves (Matsuhashi et al., 1997a), presumably by a mechanism similar to that of photoacoustic emission (Bell, 1880). Natural materials, such as wood, soil, sand, minerals and metals, also exert similar growth-regulating effects on various living cells (Ohshima et al., unpubl.). Electromagnetic oscillations striking the cells directly might be converted into sonic waves intracellularly. The opposite effect, the intracellular conversion of sound into electromagnetic waves, is also theoretically possible (Norris and Hyland, 1997).

We thank Dr. Tomio Endo of Olympus Optic Co., Dr. Kenji Sakaguchi of Mitsubishi Heavy Industries Co. and Kenshiro Takagi of the Institute of Industrial Science of the University of Tokyo for their helpful advice and discussions. This work was partially supported by a Grant-in-Aid for Scientific Research (07456052) to M. M. and a Grant-in-Aid for Scientific Research on a Priority Area (09243233) to M. M. from the Ministry of Education, Science, Sports and Culture of Japan.

\section{References}

Bell, A. G. (1880) On the production and reproduction of sound by light. Am. J. Sci. Arts Ser. 3, 20, 305-324.

Casarégola, S., Norris, V., Goldberg, M., and Holland, I. B. (1990) Identification of a $180 \mathrm{kDa}$ protein in Escherichia coli related to a yeast heavy-chain myosin. Mol. Microbiol., 4, 505-511.

Fujita, T., Shida, O., Takagi, H., Kunugita, K., Pankrushina, A. N., and Matsuhashi, M. (1996) Description of Bacillus carboniphilus sp. nov. Int. J. Syst. Bacteriol., 46, 116-118.

Grundler, W., Keilmann, F., and Fröhlich, H. (1977) Resonant growth rate response of yeast cells irradiated by weak microwaves. Phys. Lett., 62A, 463-466.

Kaiser, D. and Losick, R. (1993) How and why bacteria talk to each other. Cell, 73, 873-885.

Kimball, G. C. (1937) The growth of yeast in a magnetic field. J. Bacteriol., 35, 109-122.

Lennox, E. S. (1955) Transduction of linked genetic characters of the host by bacteriophage P1. Virology, 1, 190-206.

Matsuhashi, M., Endoh, K., Pankrushina, A. N., Watanabe, H., Yamamura, H., Komiyama, M., Endo, S., Tobi, M., Ohshima, H., Mano, Y., Hyodo, M., Kaneko, T., and Otani, S. (1997a) Growth-promoting effect of carbon material upon bacterial cells 
propagating through a distance. J. Gen. Appl. Microbiol., 43, 225-230.

Matsuhashi, M., Pankrushina, A. N., Endoh, K., Watanabe, H., Mano, Y., Hyodo, M., Fujita, T., Kunugita, K., Kaneko, T., and Otani, S. (1995) Studies on carbon material requirements for bacterial proliferation and spore germination under stress conditions: A new mechanism involving transmission of physical signals. J. Bacteriol., 177, 688-693.

Matsuhashi, M., Pankrushina, A. N., Endoh, K., Watanabe, H., Ohshima, H., Tobi, M., Endo, S., Mano, Y., Hyodo, M., Kaneko, T., Otani, S., and Yoshimura, S. (1996) Bacillus carboniphilus cells respond to growth-promoting physical signals from cells of homologous and heterologous bacteria. J. Gen. Appl. Microbiol., 42, 315-323.

Matsuhashi, M., Shindo, A., Endoh, K., Watanabe, H., Tobi, M., Endo, S., Ohshima, H., and Pankrushina, A. N. (1997b) BetaLactams and other innovative new approaches for controlling bacterial populations. In Antibacterial Therapy: Achievements, Problems and Future Perspectives, ed. by Busse, W.-D., Zeiler, H.-J., and Labischinski, H., Springer Verlag, Berlin, Heidelberg, New York, pp.17-26.

Moore, R. L. (1979) Biological effects of magnetic fields: Studies with microorganisms. Can. J. Microbiol., 25, 1145-1151.
Muir, W. H., Hildebrandt, A. C., and Riker, A. J. (1954) Plant tissue cultures produced from single isolated cells. Science, 119, 877-878.

Norris, V. and Hyland, G. J. (1997) Do bacteria sing? Molec. Microbiol., 24, 879-880.

Okada, Y., Wachi, M., Hirata, A., Suzuki, K., Nagai, K., and Matsuhashi, M. (1994) Cytoplasmic axial filaments in Escherichia coli cells: Possible function in the mechanism of chromosome segregation and cell division. J. Bacteriol., 176, 917-922.

Perego, M. and Hoch, J. A. (1991) Negative regulation of Bacillus subtilis sporulation by the spoOE gene product. J. Bacteriol., 173, 2514-2520.

Swift, S., Throup, J. P., Williams, P., Salmond, G. P. C., and Stewart, G. S. A. B. (1996) Quorum sensing: A population-density component in the determination of bacterial phenotype. TIBS, 21, 214-219.

Watson, J. D., Gilman, M., Witkowski, J., and Zoller, M. (1993) Recombinant DNA, 2nd ed., Scientific American Books, New York p. 274.

Yoshinaga, A., Hsieh, Y.-M., Sawada, T., and Gohshi, Y. (1989) Laser induced photoacoustic spectrometry with single particle sample. Anal. Sci., 5, 147-149. 